\title{
Foundry and Development of Ductile Iron Crankshaft
}

\author{
Song Liu*
}

Institute of Continuing Education, Chongqing College of Electronic Engineering, 401331, Chongqing, China

\begin{abstract}
In this paper, we introduce the production of ductile iron crankshaft of the engine status quo and development. Ductile iron crankshaft discussed smelting process, alloying and manufacturing process mode. This paper focuses on the application of isothermal hardened spheroidal graphite cast iron in the crankshaft, especially its application in the power of the engine crankshaft. We also introduce a way for casting production technique of high strength-high toughness nodular iron crankshaft. In order to increase the strength, toughness of the nodular iron crankshaft and improve casting quality, a series of investigations were carried out on the mini-amount alloying technique, control technique of iron melt eutectic point, nodularizing treating technique, curved parting method and the structure normalization process and, as the result, the high-strength and high toughness nodular iron crankshaft was successfully developed. The tensile strength of the crankshaft was increased from original $872 \mathrm{MPa}$ to $927 \mathrm{MPa}$.
\end{abstract}

Keywords: Crankshaft, development, high strength, high toughness, spheroidal graphite iron.

\section{INTRODUCTION}

Crankshaft is one of the key components of an automobile engine, its performance directly affects the car's life. Crankshaft work bear large loads and changing moment and torque effect, a common failure mode for the bending fatigue fracture and journal wear, thus requiring the crankshaft of a material having high rigidity and fatigue strength and good wear resistance. With the development of ductile iron technology, and its performance is improving, high-quality low-cost ductile iron has become an important material of the crankshaft [1]

Since 1947 ductile invention, after not long time of hard work, its tensile strength is increased to $600-900 \mathrm{MPa}$, close to exceed the level of carbon steel. Compared with forged steel, ductile iron crankshaft both manufacture simple, low cost, but also shock absorption, abrasion resistance, surface crack is not sensitive to forged steel materials do not have good characteristics, thus instead of ductile iron with a forged steel crankshaft possibilities [2].

The late 1950's, pioneered mass production of the domestic automobile factory in Nanjing YueJin brand cars ductile iron crankshaft. 60 years, The Second Car Plant became the first company to produce iron crankshaft production process in accordance with ball design and production of the car factory. To the 1970 s and 1980 s, the rapid development of small and medium sized diesel engines in China, due to the advantages of ductile iron manufacturing and economic aspects, most small and medium diesel engines are used ductile iron crankshaft, greatly promoted the application and development of ductile iron crankshaft, there have been a group specializing in the production of ductile iron crankshaft plant. In the past decade the rapid development of the automotive industry, and the construction of a number of modern ductile iron crankshaft production plant (or factory, workshop), ductile iron crankshaft has been widely used in the country [3].

Foreign ductile iron crankshaft applications are very broad, as early as the $1950 \mathrm{~s}$, foreign countries began to be applied to the crankshaft of ductile iron production, such as the United States, the first application of Ford, Chrysler Corporation, Swiss GF company, France's Renault and Citroen, Fiat of Italy, Romania Brasov car factory, has successfully applied to the crankshaft of ductile iron production. In Germany, the displacement of $2000 \mathrm{~mL}$ or less ductile iron diesel engine crankshaft $50 \%, 1500 \mathrm{~mL}$ or less displacement gasoline engine in ductile iron crankshaft $80 \%$; in the US auto industry, ductile iron crankshaft $80 \%$. Because of the advantages of manufacturing technology and the economy, ductile iron crankshaft is widely used in the automotive industry overall situation will not change much in the future.

\section{CRANKSHAFT DUCTILE IRON SMELTING}

For ductile iron smelting, domestic cupola and frequency furnace duplex melting made more. Generally after molten iron desulfurization process, molten iron desulfurization now use more porous plug desulfurization method in which nitrogen gas was blown to join $\mathrm{CaC} 2$ or complex stirring desulfurization sorbent. Desulfurization of stability for smelting iron crankshaft was of great significance, such as the use of induction furnace melting alloy components to better control range, stability ball, easy to guarantee the quality of molten iron [4].

Nodulizing treatment is an important part of the production of ductile iron crankshaft, graphite morphology 
crank body strength not only affects performance, but will affect the crankshaft fatigue strength and impact resistance. The selection of nodulizer is very important [5].

Nodulizer major domestic rare earth ferrosilicon magnesium compound nodulizer. Effect of Rare Earth has better desulfurization and balance of trace elements harmful tendencies, purification of molten iron, stable production, but play a leading role in the ball still is magnesium. Given the increasing domestic foundry desulfurization level, the ball has a tendency to lower agent RE direction of development. In addition, according to the needs cast matrix structure, the nodulizer contain $\mathrm{Ca}, \mathrm{Ba}, \mathrm{Bi}, \mathrm{Sb}$ and other elements. What kind of technology used ball when the ball, the main consideration the level of absorption rate, the reaction is stable. Many foreign factories using cover package into law, the advantage of a higher absorption rate, low smoke, low investment, to adapt to a wide range of surfaces. Domestic use more of the ball into the law Process, the absorption rate is low (typically $30 \%-50 \%$ ). Ball of yarn feeding method recently developed a ball of new technology, the advantage of a smooth response, low temperature loss, was gradually extended.

Inoculation is essential liquid iron ball after a step. Currently, $75 \%$ of the domestic commonly used siliconsilicon alloy, foreign ductile iron inoculant applied more zirconium ferrosilicon, ferrosilicon manganese, zirconium and calcium, barium compound inoculant, which can delay the decay time of zirconium manganese can be reduced melting point, so that even conceived. Efficient use of inoculant can effectively increase the graphite core, grain refinement, slow breeding decay time. Currently, stream inoculation method widely adopted in the United States, can effectively control the inoculant in liquid iron distribution uniformity. Endo-breeding method is often used in combination with other breeding methods, it is a complex process to strengthen the inoculation. In addition, the newly developed method of feeding wire breeding process, is a breeding methods and the ball of yarn feeding method simultaneously [6].

\section{CAST DUCTILE IRON CRANKSHAFT ALLOYED}

Research data show that, compared with pearlite matrix ferrite matrix organization has better fatigue strength properties, and this is one of the important performance required to have a crankshaft. Meanwhile, the pearlite matrix structure has a higher room temperature tensile strength and abrasion resistance. Therefore, in the production of ductile iron crankshaft, the matrix organization based in pearlite matrix, typically QT600, QT700, QT800 or QT900 grades generally require more than $2 \%$ elongation. For QT600, QT700, the adoption of cast production which can stably achieve the required performance; and for QT800, QT900 and other brands of high production, many factories are achieved by heat treatment, which will undoubtedly increase crankshaft manufacturing costs, and achieve Related brands cast crankshaft has a large cost advantage.

Many promoting matrix pearlite structure, alloying elements may be employed, e.g. $\mathrm{Cu}, \mathrm{Cr}, \mathrm{Mo}, \mathrm{Ni}, \mathrm{Sn}$ and other conventional alloying elements, and such as $\mathrm{Sb}, \mathrm{Bi}$ and other trace alloying elements also has good function to promote the formation of pearlite, but usually a single alloying elements cannot properly achieve high grades and performance. Studies have shown that the use of binary alloy or multi-alloy often than a single alloy addition in the form of having a multiplier effect. For the above grades, it usually alloyed $\mathrm{Cu}$ as a major element, $\mathrm{Cu}$ has a good performance in promoting the formation of pearlite, in favor of the graphite eutectic phase and thinning, graphite ball round, and will not promote carbide formation. Using $\mathrm{Cu}-\mathrm{Mo}, \mathrm{Cu}-\mathrm{Ni}$, $\mathrm{Cu}-\mathrm{Cr}$ binary alloy, etc. may be implemented QT600, QT700 grade cast production, but easy to produce carbide elements such as $\mathrm{Cr}$, etc. should be noted that use of the control, while the element also hinder graphitization influence the final ball of the effect.

For QT800-2 grades, cast stable production often requires a variety of processes were integrated, of course, is an important factor alloyed grades guarantee full performance. Tests showed that $\mathrm{Cu}-\mathrm{Sb}, \mathrm{Cu}-\mathrm{Sn}$-based alloy, using $\mathrm{Mo}, \mathrm{Ni}$, etc., as an additional element, the performance requirements can be achieved grades. Such as the use of $\mathrm{Cu}-$ $\mathrm{Sb}$ alloy, even up QT900-2 grades, which play a leading role in the trace element $\mathrm{Sb}, \mathrm{Sb}$ element is a trace element, is generally not used in the production abroad, because of its relatively small amount is added, range narrow, not conducive to production control. But it has a very good increase $\mathrm{Sb}$ matrix pearlite content characteristics, in a suitable range will not promote carbide production, and increase the amount of graphite balls, improved roundness, particularly in large section castings applications with good effect, can significantly improve the strength properties. Sn effect similar to $\mathrm{Sb}$, is a strong pearlite stabilizing elements, widely used in high-grade gray iron, vermicular iron and ductile iron foundry, its amount is usually maintained at $0.02 \%$ to $0.05 \%$, does not promote carbide produce, can significantly improve the strength, hardness, but if Sn is added an excessive amount will cause a decrease in toughness castings.

\section{CAST DUCTILE IRON CRANKSHAFT PRODUCT- ION PROCESS}

For the production of cast QT800, QT900 crankshaft castings and other high grades, many manufacturers have done a lot of research experience, including the alloying research is not all, usually requires a combination of the size of the crankshaft and the use of iron coated sand mold, shell filled casting balls come together to achieve, and these molding process in the production Qt600, QT700 grades crankshaft, camshaft also a large number of applications, and become the development trend of a molding. Compared with conventional shock pressure, air impact, high pressure, such as modeling the way, iron coated sand mold, shell filled pellet production process can achieve rapid cooling of the crankshaft and the crank shape can be achieved through shell-type or iron-type adjust the order of solidification aim to reduce internal stress, help feeding, can effectively improve the pearlite content, refine and reduce the pearlite lamellar spacing, thereby increasing the strength of performance, but also has a high surface accuracy, small allowance, high production efficiency production stability and other characteristics. 
Iron coated sand mold, shell filled pill production process for achieving stable production of high-grade QT800-2 crankshaft is important, with the organic combination of alloying, can greatly improve the mechanical properties of the crankshaft. But the requirements for bulk sampling, limited to the crankshaft of different types, sizes, often using the above scheme cannot achieve stability QT800-2 requirements, which need to play in the crank case time and hit me on the back cooling mode to do the work, to further enhance the crankshaft body pearlite content, refine the pearlite spacing, thus improving performance requires strict production control.

\section{APPLICATION OF AUSTERMENPERED DUCTILE IRON (ADI) IN THE CRANKSHAFT}

As manufacturing crankshaft material, it has high fatigue strength (bending, torsion), abrasion resistance and rigidity. From the analysis, the material properties of ductile iron, the isothermal hardened spheroidal graphite cast iron is an ideal engineering material crankshaft. Generally agreed that, if the ball a tensile strength of $800 \mathrm{MPa}$ iron still cannot meet the requirements, can be isothermal hardened spheroidal graphite cast iron instead of forged steel. Volvo cars crank, some of Ford Motor Company engine crankshaft, a number of high-power diesel engine crankshaft are used isothermal hardened spheroidal graphite cast iron.

Since the 1960s, ductile iron crankshaft due to material and processing costs, and therefore favored by the majority of designers, and has been widely used in the automobile and low-load cars, but limited to ordinary iron ball low bending fatigue strength than steel forgings restrictions, it is particularly heavy loads at moderate load on the engine is difficult to achieve the required performance car. Engine crankshaft service conditions are very complex and demanding, in practice a lot of crank failure accident statistics show that the bending and torsional fatigue fracture is the main form of damage to the crankshaft, particularly bending fatigue strength failure is most common. Isothermal hardened spheroidal graphite cast iron material having a high flexural fatigue strength and overall strength, but because of its austenite matrix, a significant hardening effect, after fillet rolling, the transformation, the formation of a high The residual compressive stress and improve fatigue strength of the crankshaft. Therefore, ductile iron crankshaft replace some of forged steel crankshaft has great potential, but isothermal hardened spheroidal graphite cast iron crankshaft forgings reduce their quality of representing about $10 \%$ of the manufacturing cost can be greatly reduced, as a new crankshaft material with very good application prospect.

In China, Nanjing University of Technology and Engineering for isothermal hardened spheroidal graphite cast iron with a car engine 368Q: crankshaft tested. Bench test, reliability testing and full load full speed $30,000 \mathrm{~km}$ road test, through ministerial-level appraisal, the safety factor 1.7, higher than the safety factor of imported forged steel crankshaft (1.6), the main journal and rod journal amount of wear much lower than the machinery of the standard. Conventional mechanical properties of ductile iron crankshaft, fatigue strength, abrasion resistance, manufacturability, safety and reliability to meet the design requirements, economic benefit. According to cost projections show that imports forged steel crankshaft: Domestic $40 \mathrm{Cr}$ forged steel crankshaft isothermal hardened spheroidal graphite cast iron song $=2.7: 1.84: 1$.

Isothermal hardened spheroidal graphite cast iron material instead of forged steel crankshaft, compared to the static strength and flexural fatigue strength, isothermal hardened spheroidal graphite cast iron crankshaft capable of high-power turbocharged diesel engine service conditions, and it also has a significant advantage in terms of cost, with isothermal hardened spheroidal graphite cast iron production of high-power turbocharged diesel engine crankshaft is a great technology, economic efficiency, and should concern the domestic automobile industry.

\section{CASTING PRODUCTION TECHNIQUE OF HIGH STRENGTH-HIGH TOUGHNESS NODULAR IRON CRANKSHAFT}

Engines are mainly used in the automotive, engineering machinery, agricultural machinery, and defense equipment and the like. As a core component of the engine crankshaft, plays a key role in energy conversion and power output process. Ductile iron crankshaft has good abrasion resistance, shock resistance, machinability and high cost, etc. are widely used. To meet the higher requirements of energy saving, high speed toward the new medium-power engine, supercharger, high-power direction; With crankshaft bear the load increases, the requirements of the crankshaft has better mechanical properties [7].

High-performance ductile iron tends to have two classes: $\mathrm{Cu}-\mathrm{Mo}$ ductile iron $[8,9]$, the second is isothermal hardened spheroidal graphite cast iron (ADI) $\mathrm{Cu}$-Mo ductile iron, Ni$\mathrm{Cu}$ and $\mathrm{Ni}-\mathrm{Mo}$ ductile iron ductile iron with high tensile strength, $\mathrm{w}(\mathrm{Cu})$ content of about $5 \%$, w (Mo) content of about $0.35 \%$, Mo is a very high melting point, you can join in an electric furnace. Mo is a carbide-forming element, easy to segregate at the grain boundaries, it can't be eliminated by heat treatment, with w (Mo) amount increases, although the strength of the material increased, but the toughness is decreased, can't meet the service requirements of the new engine crankshaft. Although the performance of ADI and forged steel can be comparable, but the process is complicated and difficult to overcome technical difficulties, although the study abroad but rarely used on the crankshaft. The existence of traditional ductile iron crankshaft two major problems: You can't have high strength and high toughness at the same time guarantee; secondly, can't achieve the high quality of the crankshaft consistency, become a bottleneck restricting the development of the engine [10].

\subsection{Test Method}

\subsubsection{Micro-Alloying Technology}

Analyzing the advantages and disadvantages of $\mathrm{Cu}, \mathrm{Ni}$, $\mathrm{Sn}, \mathrm{Cr}$ and other alloying elements, orthogonal test, carried out by different proportions of trial and error to get a lot of technical data, and ultimately determined by $\mathrm{Cu}-\mathrm{Sn}$ alloy instead of the $\mathrm{Cu}-\mathrm{Mo}$ alloy.

Sn melting point of only 230 degrees Celsius, the liquid iron melts instantly and completely spread. By Sn inoculant 
formulated into not only give full play to the role of Sn alloy, but also strengthen the inoculation effect. Solidification of molten iron, atoms are adsorbed on graphite eutectic around the ball, obstruction atomic diffusion, destroyed the grain growth conditions, the grain is refined; surrounds the graphite spheres $\mathrm{Sn}$ atoms, slowing from the matrix $\mathrm{C}$ diffusion of the graphite nodules, thus promoting the formation of pearlite, pearlite to improve the stability, small graphite balls, homogeneous, to improve the strength and toughness of the material.

By scanning electron microscopy and electron probe further found that the addition of $\mathrm{Sn}, \mathrm{Cu}$ organizational changes segregation status, $\mathrm{Cu}$ element becomes uniform in the distribution of material within the matrix, thereby improving the uniformity of the organization, improve the mechanical properties of the crankshaft. Experimentally determined, w $(\mathrm{Sn})$ volume control at about $0.02 \%$, w $(\mathrm{Cu})$ volume is still controlled at about 0.5 percent, to cancel $0.6 \%$ $\mathrm{Mo}-\mathrm{Fe}$ join, annual savings of more than 80 tons of Mo-Fe, the cost per ton decreased crankshaft $15 \%$.

As can be seen from Table 1, compared with the domestic $\mathrm{Cu}-\mathrm{Mo}$ ductile iron crankshaft, $\mathrm{Cu}-\mathrm{Sn}$ ductile iron crankshaft tensile strength, elongation and impact toughness significantly improved crankshaft bearing capacity and reliability are improved, extended service life, reaching levels $42 \mathrm{CrMoA}$ forged steel crankshaft.

Table 1. Mechanical properties.

\begin{tabular}{|c|c|c|}
\hline Measures & $\begin{array}{c}\text { Cu-Mo Ductile } \\
\text { Iron Crankshaft }\end{array}$ & $\begin{array}{c}\text { Cu-Sn Ductile } \\
\text { Iron Crankshaft }\end{array}$ \\
\hline \hline Tensile strength /MPa & 872 & 927 \\
\hline Elongation (\%) & 2.6 & 3.6 \\
\hline Impact toughness /J.cm-2 & 26 & 37 \\
\hline
\end{tabular}

\subsubsection{Iron Liquid Eutectic Point Control Technology}

Liquid iron with a eutectic composition, crystalline narrow, easy feeding technology is the best. Production process control is usually in the vicinity of molten iron $\mathrm{CE}$ eutectic point, in order to obtain high-quality castings. Production process, at the same $\mathrm{CE}$, pouring temperature and other conditions, different sources of charge (pig iron factory conversion or join rescaling etc.), the shrinkage of scrap vary widely, sometimes shrinkage reject rate below $1 \%$, sometimes up to $30 \%$ [11].

After the study found that both changes in ore waste slag or charge added to liquid iron five elements $\mathrm{C}, \mathrm{Si}, \mathrm{S}, \mathrm{P}$ will be adjusted to within the required range of features, and lots of trace elements did not control and can't control. Particularly where domestic ore tense, rely heavily on imports of the situation, the use of slag is from different regions, resulting in trace element iron was the diversity and variability, nowhere more so casting enterprises, quality fluctuations.

Castings for intrinsic quality caused by trace element contents changing volatility issues that affect the integrated elements in liquid iron eutectic point, combined with iron solidification curve, developed the original iron liquid eutectic point control technology to solve the microelements in iron puzzle liquid eutectic point impact, the iron was controllable CE real intrinsic quality has been effectively guaranteed. Shrinkage defects increased from $1.44 \%$ to $0.19 \%$, far lower than Japan, Germany, well-known enterprises indicators. Improve the internal consistency of the quality of the crankshaft, the crankshaft tends to significantly reduce fatigue fracture, broken crank shaft rate from $450 \mathrm{ppm}$ down to $120 \mathrm{ppm}$.

\subsubsection{Nodulizing Treatment Technology}

Foundry method has been in use into the molten iron ball handling, ball agent in severe burning elements $\mathrm{Mg}$, instability using large ball agent, ball quality, within the tissue contains a lot of flake and vermicular graphite, the matrix split effect, and affect performance, high temperature loss, slag volume, casting scrap rate [12].

Based nodulizer $\mathrm{Mg}$ element in high-temperature gasification characteristics, design a set of ball, cast as one of the processing package, developed a sealed ball processing complete sets of equipment for high-volume assembly line, the ball treatment in a sealed process carried the bag nodulizer when the temperature of molten iron generate a lot of $\mathrm{Mg}$ vapor pressure within the package instant rise, a positive pressure, prompting ball reaction is carried out in an oxygen-free state under positive pressure to prevent the oxidation of $\mathrm{Mg}$ burning, stable quality ball controllable [13].

$\mathrm{Mg}$ absorption rate increased from $30 \%$ to $40 \%$ to $60 \%$, reducing the average amount nodulizer $30 \%$ ball rate of $90 \%$ graphite ball round, the quality of the ball (Figs. 1, 2). Ball process temperature of molten iron loss increased from 70 degrees down to 40 degrees Celsius, is conducive to inclusion float, reducing slag defects; greatly reduces the light smoke $\mathrm{Mg}$ dust formed during the reaction, greatly improve the working environment, saving energy and reducing drain effect is very significant [14].

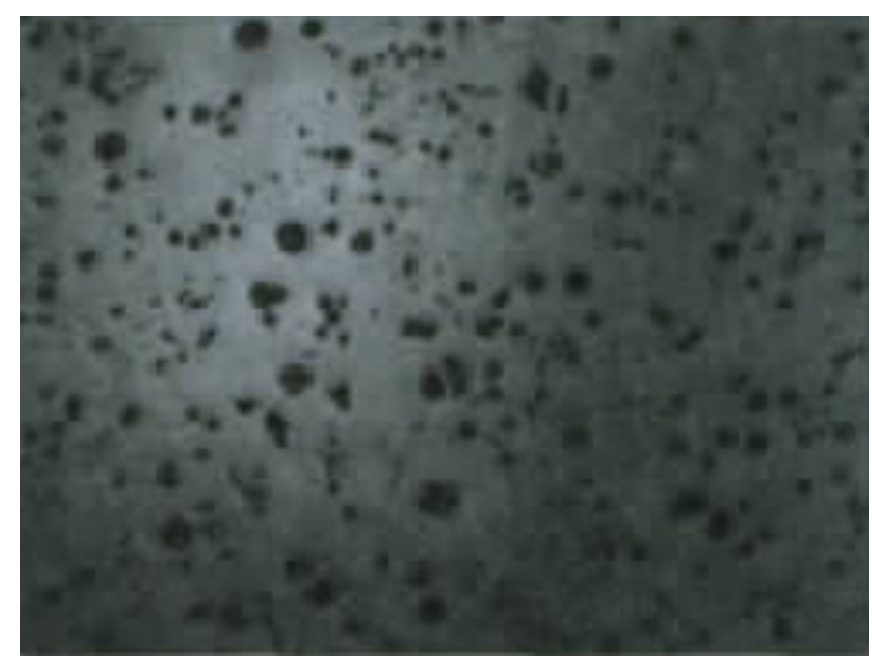

Fig. (1). Pour-over nodulizing treatment.

\subsubsection{Surface Type Casting Technology}

Connecting rod journal is not in the same plane of the crankshaft (crankshaft casting quality $70 \sim 80 \mathrm{~kg}$, the journal diameter $85 \sim 100 \mathrm{~mm}$, the total length of $1000 \mathrm{~mm}$ ), many manufacturers have adopted the method to fill sand core 
surface type of plane typing. It will result in terms of the sixcylinder crankshaft $b, c, d$, e link shaft at the parting line angle of 120 degrees, lower space, four connecting rod journal need sand to form the core. Core system requires specialized equipment and tooling, including with sand, plus resin, mixed system, inspection, radio batteries, paint brush and dry. Complicated process, high labor intensity, low productivity, high production costs, environmental pollution, and the sand core is easy to produce high temperature combustion such as porosity, improper under the core defect can cause the crankshaft RPM, crankshaft rejection rate.

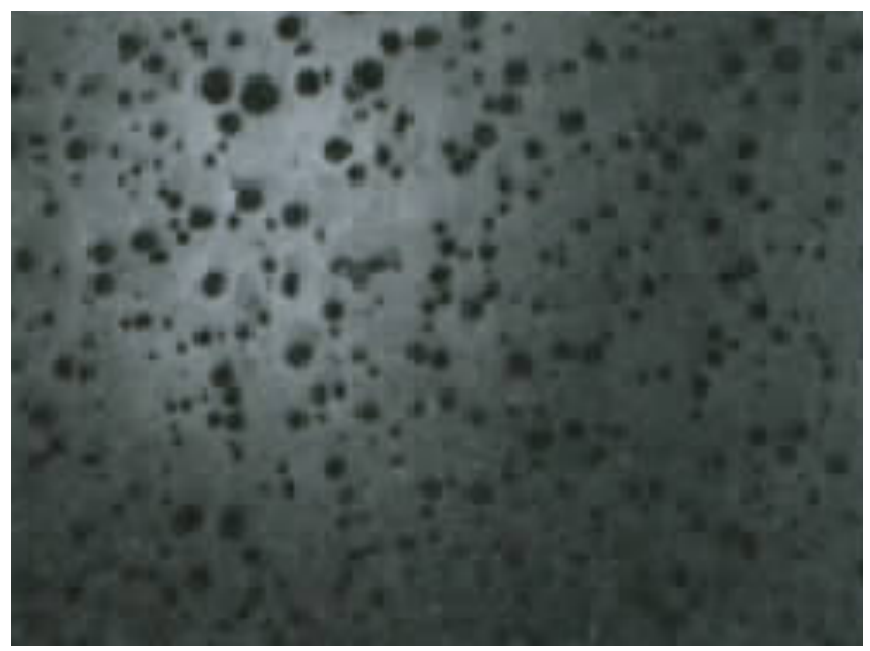

Fig. (2). Closed nodulizing treatment.

To solve the problem, take a typing surface casting techniques. Tooling design along both ends of the spindle and the link shaft center-line, who can't play mode crankpin $\mathrm{b}, \mathrm{c}, \mathrm{d}$, e part in an intermediate position between the center rod journals select a face, the connecting rod journal divided into two types, the draft angle changed from the original linear arc slash type. Avoid modeling process produces sharp, easy to swap the sand, while the circular surface can increase the sand strength, ease from the model, so the original form automatically when the shape formed by the core portion, the abolition of the core, improve the temperature field, and designed on the basis of new gating system, to achieve control solidification, eliminating the need for system core, core setting, cold iron three processes to achieve non-core casting.

This technology simplifies the operation process, avoiding the sand casting defects; saving raw materials, casting about cost reduction; reduce labor intensity, improve production efficiency; the eradication of harmful gases generated by the core, the working environment has been greatly improved, to ensure that the workers' health.

\subsubsection{Technology and Equipment for Tissue Homogenization Normalizing Process}

Typically normalizing way is that the work-piece using box-type electric heating, normalizing furnace temperature of 800 degrees Celsius, baked flat work-piece, air mist cooling. Fog and wind blow from only one direction, the work-piece is on his back to the wind direction and the direction of the fog can't even cooling, there is a yin and yang side. Due to the different cooling conditions, the volume fraction of the various parts of pearlite, pearlite spacing and grain size are there is a big difference normalizing the work-piece, leading to different parts of the mechanical properties of the work-piece varies greatly. At the same time, different cooling conditions, the stress and thermal stress, there are significant differences, resulting in a greater deformation of the work-piece.

\subsection{Result of Test}

Through the above study, ductile iron crankshaft increase the tensile strength increased from $872 \mathrm{MPa}$ to $927 \mathrm{MPa}$, impact toughness from the $26 \mathrm{~J} / \mathrm{cm} 2$ to $40 \mathrm{~J} / \mathrm{cm} 2$. The project ductile iron crankshaft fatigue moment increased by $38 \%, 14.3 \%$, increase the safety factor, the coefficient of variation decreased performance than forged steel crankshaft, improved reliability, longer life! OEM purchase prices were overcome forged steel crankshaft large investment in equipment, processing complex, high energy consumption and high cost, to achieve the iron and steel. The crankshaft cast microstructure as shown in the Table 2 . Microstructure and mechanical properties are shown in Table 3 after normalizing. Fully meet the design requirements.

\section{CONCLUSION}

Ductile its excellent physical and mechanical properties, it has been widely used in the manufacturing of the crankshaft. With the development of ductile iron smelting and alloying technology and isothermal hardened spheroidal graphite cast iron, ductile iron continuously improve performance. To save costs, the use of ductile iron production engines replace forged steel crankshaft, it is the development trend of the crankshaft production. Iron-type clad sand and shell casting Iron Shot mode ensures pearlite content of ductile iron substrate to achieve small spacing of pearlite, compact, improve the quality of and performance of the crankshaft, suitable for crankshaft castings. For small and medium power engine crankshaft production can be cast pearlite ductile iron, or additional surface hardening process; and isothermal hardened spheroidal graphite cast iron its excellent mechanical properties, to play a greater role in the manufacture of high-power engine crankshaft.

Table 2. Crankshaft cast microstructure.

\begin{tabular}{|c|c|c|c|c|c|}
\hline ID & Pearlite (\%) & Nodulizing Level & Graphite Size & Cementite (\%) & Phosphorus Eutectic (\%) \\
\hline \hline 1 & 75 & $2 \sim 3$ & $5 \sim 6$ & $<0.5$ & $<0.5$ \\
\hline 2 & 70 & 2 & 6 & $<0.5$ & $<0.5$ \\
\hline 3 & $65 \sim 70$ & $2 \sim 3$ & $5 \sim 6$ & $<0.5$ & $<0.5$ \\
\hline
\end{tabular}


Table 3. The normalized microstructure and properties of crank.

\begin{tabular}{|c|c|c|c|c|}
\hline ID & Pearlite \% & Hardness (HB) & $\sigma(\mathbf{M P a})$ & $\delta(\mathbf{\%})$ \\
\hline \hline 1 & 95 & 263 & 813 & 2.3 \\
\hline 2 & 95 & 237 & 927 & 4.3 \\
\hline 3 & 95 & 240 & 885 & 2.7 \\
\hline
\end{tabular}

\section{CONFLICT OF INTEREST}

The authors confirm that this article content has no conflict of interest.

\section{ACKNOWLEDGEMENTS}

Declared none.

\section{REFERENCE}

C. Wang, "Spheroidal Graphite Crankshaft Foundry and Development," Automobile Technology \& Material, no. 3, pp. 1-3, 2006.

[2] T. Watmough, and M. J. Malatesta, "Strengthening of Ductile Iron for Crankshaft Application," Transaction of AFS, vol. 84, no. 32, pp. 83-99, 1984

[3] Q. Cai, and B. Wei, "Recent development of ductile cast iron production technology in China," China Foundry, vol. 5, no. 2, pp. 82-91, 2008.
[4] M. M. Haque, and J. M. Young, "Production of spheroidal graphite aluminum cast iron cast iron and the factors affecting it," Materials Processing Technology, no. 50, pp. 186-192, 1995.

[5] Z. H. Li, and Y. Li, "Evaluation of melt quality and graphite degeneration prediction in heavy section ductile iron," Metallurgical and Materials Transactions A, vol. 36, no. 9, pp. 2455-2460, 2005.

[6] Z. Zhang, H. M. Flower, and Y. Y. Niu, "Classification of degenerate graphite and its formation processes in heavy section ductile iron," Materials Science and Technology, vol. 5, no. 7, pp. 657-664, 1989.

[7] S. Yang, J. Con, and H. Sun, "Casting Production Technique of High Strength-High Toughness Nodular Iron Crankshaft," Nodular Iron \& Gray Iron, no. 6, pp. 39-43, 2011.

[8] G. Liu, Y. Zhang, and X. Yi, "Estimate of Application Prospect of Ductile Iron Crankshafts," Research \& Discussion, no. 1, pp. 1-7, 2005

[9] G. Liu, and H. Wang, "Development and Application of ADI Crankshaft for Turbocharged Diesel Engine," Modern Cast Iron, no. 2, pp. 13-19, 2007.

[10] Y. Feng, and W. Su, "Improvement on Foundry Process for Nodular Cast Iron Crankshaft with Heavy Section Used in Reciprocating Compressor," Hot Working Technology, vol. 40, no. 3, pp. 53-55, 2011 .

[11] E. Fras, K. Wiencek, M. Gorny, and H. F. Lpez, "Graphite Nodule and Eutectic Cell Count in Cast Iron: Theoretical Model Based on WeiBull-Statistics and Experimental Verification," Metallurgical and Materials Transactions A, vol. 38, no. 2, pp. 385-395, 2007.

[12] R. Zhang, "Seal of nodular cast iron ball treatment," Acta Metallurgica Sinica, vol. 4, no. 2, pp. 155-161, 1959.

[13] R. K. Buhar, "Vermiculite Graphite Formation Heavy Section Nodular Iron Castings," Transaction of AFS, no. 76, pp. 467-503, 1968

[14] C. Wang, Y. Sun, and M. Li, "An review of common nodulizing treatment processes," Modern Cast Iron, no. 3, pp. 62-64, 2004.

(C) Song Liu; Licensee Bentham Open.

This is an open access article licensed under the terms of the (https://creativecommons.org/licenses/by/4.0/legalcode ), which permits unrestricted, non-commercial use, distribution and reproduction in any medium, provided the work is properly cited. 